\title{
Effects of the Job Stress of Nursing Care Workers at Nursing Homes on Burnout - Focusing on the Control Effects of Emotional Intelligence -
}

\author{
Sun-Yeol Choi ${ }^{1}$, Jea-Ug Ko ${ }^{2}$ \\ ${ }^{1}$ Student, Department of Social Welfare, Catholic Kwandong University, Korea, \\ uncle5326@hanmail.net \\ ${ }^{2}$ Professor, Department of Social Welfare, Catholic Kwandong University, Korea, \\ kojea62@cku.ac.kr
}

Corresponding author: Jea-Ug Ko

\begin{abstract}
This study is aimed to determine the effects of the emotional aspect on human resources management to secure and manage human resources equipped with core capabilities. The reason is that the human service industry, including long-term home care institutions, primarily depends on human resources as human service becomes the core. This study conducted a survey on 204 nursing care workers at nursing homes located in G Province and an empirical analysis was performed with the collected data. The study results are presented as follows: First, job stress significantly affected job burnout. Second, this study verified emotional intelligence's control effect in the relationship between job stress and job burnout. The emotional intelligence's control effect was significant. This means that private nursing homes' non-profit management mindset and dynamic intelligence training for nursing care workers to cope with job stress actively are essential. As emotional intelligence is improved with learning and practice, the policy or a further study on the development of dynamic capabilities should be carried out. Specifically, guidelines for the self-development and life quality improvement of nursing care workers, the long-term care insurance system's core human resources, and efficient, long-term home care institutions' efficient operations need to be presented.
\end{abstract}

Keywords: Nursing Homes, Nursing Care Workers, Job Stress, Job Burnout, Emotional Intelligence

\section{Introduction}

\subsection{Need for the study}

Job stress of nursing care workers at nursing homes seriously affects their job burnout, so the service quality for the patients tends to decline. This study aimed to examine the effects of nursing care workers' job stress on job burnout by identifying the job stress factors of the nursing care workers and whether emotional intelligence has a control effect between job stress and job burnout. The previous related studies report that job stress is a primary predicting variable of nursing care workers' job burnout. Suppose nursing care workers experience job stress, and it is accumulated without being solved; in that case, they select to transfer jobs or quit their jobs due to emotional and psychological exhaustion, namely job burnout. If the burnout occurs to one organization member, it negatively affects other members in

*This paper has revised and supplemented the lead author's master's degree thesis.

Received: October 15, 2020; 1st Review Result: December 2, 2020; 2nd Review Result: January 15, 2021

Accepted: February 26, 2021 
the same organization[1]. The burnout of nursing care workers negatively affects job attitude, job satisfaction, job performance, job achievement, and self-concept, but the quality of service may decline and ultimately affect the quality of life of the elderly[2].

Meanwhile, emotion intelligence was defined as an ability to control and distinguish one's emotions and moods from others' using the information obtained through a capability to sense and determine one's feelings and attitudes from others'[3]. Through the previous studies, the nursing care workers experiencing job burnout due to job stress can predict the ease and control of job burnout caused by job stress with emotional intelligence's functional control ability. In this study, emotional intelligence showing a control effect in the relationship between job stress and job burnout among nursing caseworkers carries substantial meaning. This is an opportunity for nursing care workers to be reassured that job stress reduction and emotional intelligence development and retention are necessary for them. It can also make existing theory and information more valuable and used more diversely. Through nursing care workers' job professionalism and attitude change for subjects, clearer theoretical foundations on long-term nursing service quality can be provided.

\subsection{Research Problems}

This study its purpose through the change of nursing care workers, the core workers of long-term care insurance, and the following questions will be addressed:

First, "Does nursing care workers' job stress affect job burnout?"

Second, "Does emotional intelligence play a control role in the effects of nursing care workers' job stress on job burnout?"

\section{Research Method}

The following research models were set to achieve the purpose of this study:

\subsection{Research Models}
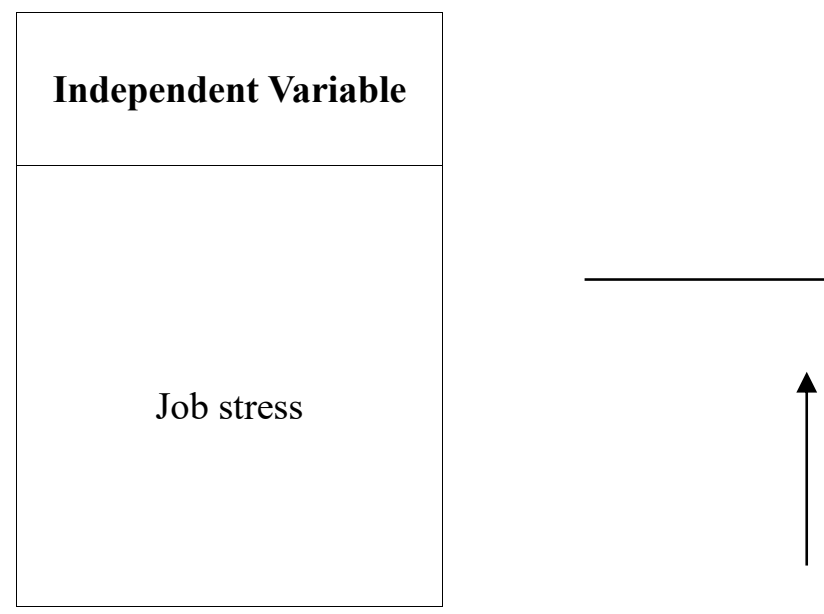

Dependent Variable

Job burnout

- Emotional exhaustion

- Dehumanization

- Decline in a personal desire to accomplish 


\subsection{Research Hypotheses}

Hypothesis 1 . The nursing care workers' job stress will affect job burnout.

Hypothesis 2. Emotional intelligence will play a controlling role in the effects of nursing care workers' job stress on job burnout.

\subsection{Data Collection and Sample}

This study targeted the nursing care workers at the nursing homes located in G Province. The data collection was conducted through a questionnaire survey to achieve the purpose of the study, and it was completed after the participants' consent was gained. The questionnaire survey period was for two weeks, from April 6 until April 2020. The questionnaire copies were distributed to the nursing care workers after sufficiently explaining the purpose of this study, and then the response copies were collected. Two hundred thirty questionnaire copies were distributed, and 204 copies were ultimately collected, and the data collection for verification of research hypotheses was performed in two steps. Indepth interviews were carried out, targeting the nursing care workers, and significant factors related to job stress, job burnout, and emotional intelligence were drawn. Based on these dynamics, the final questions were drawn through the operational definition used in the literature review.

The survey questions are composed of core variables measuring items and were carried out using selfrecording type, targeting 204 adult males and females employed as nursing care workers.

\subsection{Operational Definition of Variables}

\subsubsection{Job Stress}

This study used 12 questions after partially revising the job stress measuring tool developed by Ha Mi-Na[4] and the measuring tool used by Ivancevich and Matterson[5] as this revision was found suitable for this study's objectives.

Each question was measured by a 5-point Likert scale: 1 point - Strongly disagree, 2 points Disagree, 3 points - Neutral, 4 points - Agree, 5 points - Strongly agree. For the measurement of job stress, the questions consisted of three areas: four questions related to senior workers, four questions on excessive role factors, and four questions on wage/salary and reward.

\subsubsection{Burnout}

To measure social workers' burnout level, this study used questionnaire questions translated by Ahn Soo-Gyung[6] after revising them. Each question consisted of Strongly Agree (5 points), Agree (4), Neutral (3), Disagree (2), and Strongly Disagree (1) remarks. As the score gets higher, the nursing care workers feel more burnout. The questions by sub-factor of burnout consisted of 20 questions: eight questions on emotional exhaustion, six on the lack of sense of accomplishment, and six questions on dehumanization.

\subsubsection{Emotional Intelligence}

Wong and Law Emotional Intelligence Scale (WLEIS), an emotional intelligence measuring tool developed by Wong and Law[7], was used for this study. It consisted of 16 questions: four questions on one's emotion understanding, others' emotion understanding, emotion control, and emotion utilization, respectively. Each question was measured using the 5-point Likert scale, ranging from Strongly Agree (5 points) to Strongly Disagree (1). A higher score meant a higher self-understanding of emotion. 


\subsection{Method to Analyze Data}

This study conducted a questionnaire survey targeting nursing care workers at nursing homes and analyzed the collected questionnaire responses. SPSS 20.0 was used as an analysis tool. For reliability verification of the measuring tool, the questions' reliability was measured using Cronbach's alpha coefficient, and factor analysis on each question was performed for the validity test. Although the validity of the questions was already carried out, exploratory factor analysis was conducted to consider a possibility of error occurrence in the translation process. Lastly, this study carried out a regression analysis to analyze the effects of job stress on job burnout, and a hierarchical regression analysis was performed to check the control effect of emotional intelligence in the effects of job stress on job burnout.

\section{Results}

\subsection{Analytical Results of Measurement's Reliability and Validity}

This study carried out an exploratory factor analysis to test the validity of component concepts. As a result of the KMO and Bartlett test, the Kaiser-Meyer-Olkin measure value was .893. According to Bartlett's sphericity test results, significance probability was $p=.000$, and so adequacy was ensured. The principal component analysis was carried out using the Varimax rotation method and the factor extraction method to test the component items' validity. As a result of the test, all questions' factor loading was 0.6 or more, so high validity was ensured. The Cronbach's alpha coefficient to confirm reliability was 0.7 or more, and so it was verified as an acceptable level.

\subsection{Effects of Job Stress on Job Burnout}

To verify the effects, a regression analysis on sub-hypotheses was carried out. The regression analysis results verifying job stress's effect on emotional exhaustion, which is a sub-factor of job burnout, are shown in [Table 1]. According to the verification result, job stress significantly and positively affected emotional exhaustion $(b=.725, \mathrm{t}=14.940, \mathrm{p}<.001)$.

Therefore, the hypothesis that job stress would have a significant positive effect on emotional exhaustion was adopted.

[Table 1] Effects of Job Stress on Emotional Exhaustion

\begin{tabular}{|c|c|c|c|c|c|c|}
\hline \multirow{2}{*}{ Model } & \multicolumn{2}{|c|}{$\begin{array}{l}\text { Non-standardized } \\
\text { Coefficient }\end{array}$} & \multirow{2}{*}{$\begin{array}{l}\text { Standardized } \\
\text { Coefficient } \\
\text { (b) }\end{array}$} & \multirow{2}{*}{$\mathrm{t}$} & \multirow{2}{*}{$\mathrm{p}$} & \multirow{2}{*}{ Result } \\
\hline & B & $\begin{array}{l}\text { Standard } \\
\text { Error }\end{array}$ & & & & \\
\hline (Constant) & -.187 & .162 & & -1.157 & $*$ & \multirow{2}{*}{ Adopted } \\
\hline $\begin{array}{l}\text { Job stress } \rightarrow \\
\text { emotional exhaustion }\end{array}$ & .876 & .059 & .725 & 14.940 & $* * *$ & \\
\hline
\end{tabular}

$* \mathrm{p}<.05, * * \mathrm{p}<.01, * * * \mathrm{p}<.001$ 
The regression analysis results for verification on the effects of job stress on dehumanization are shown in [Table 2]. According to the verification result, job stress significantly affected dehumanization $(\mathrm{b}=.409, \mathrm{t}=6.366, \mathrm{p}<.001)$.

Thus, the hypothesis that job stress would have a significant positive effect on dehumanization was adopted.

[Table 2] Effects of Job Stress on Dehumanization

\begin{tabular}{|c|c|c|c|c|c|c|}
\hline \multirow{2}{*}{ Model } & \multicolumn{2}{|c|}{$\begin{array}{l}\text { Non-standardized } \\
\text { Coefficient }\end{array}$} & \multirow{2}{*}{$\begin{array}{c}\text { Standardized } \\
\text { Coefficient } \\
\text { (b) }\end{array}$} & \multirow{2}{*}{$\mathrm{t}$} & \multirow{2}{*}{$\mathrm{p}$} & \multirow{2}{*}{ Result } \\
\hline & B & $\begin{array}{l}\text { Standard } \\
\text { Error }\end{array}$ & & & & \\
\hline (Constant) & .761 & .169 & & 4.501 & $* * *$ & \multirow{2}{*}{ Adopted } \\
\hline $\begin{array}{c}\text { Job stress } \rightarrow \\
\text { Dehumanization }\end{array}$ & .389 & .061 & .409 & 6.366 & $* * *$ & \\
\hline
\end{tabular}

The regression analysis results to verify the effects of job stress on the decline in personal desire to accomplish is shown in [Table 3]. According to the verification result, job stress significantly affected the decline of personal desire to accomplish $(b=.415, \mathrm{t}=6.490, \mathrm{p}<.001)$.

Therefore the hypothesis that job stress would have a significant positive effect on the decline of personal desire to accomplish was adopted.

[Table 3] Effects of Job Stress on Personal Desire to Accomplish

\begin{tabular}{|c|c|c|c|c|c|c|}
\hline \multirow{2}{*}{ Model } & \multicolumn{2}{|c|}{$\begin{array}{l}\text { Non-standardized } \\
\text { Coefficient }\end{array}$} & \multirow{2}{*}{$\begin{array}{l}\text { Standardized } \\
\text { Coefficient } \\
\text { (b) }\end{array}$} & \multirow{2}{*}{$\mathrm{t}$} & \multirow{2}{*}{$\mathrm{p}$} & \multirow{2}{*}{ Result } \\
\hline & B & $\begin{array}{l}\text { Standard } \\
\text { Error }\end{array}$ & & & & \\
\hline (Constant) & .786 & .196 & & 4.014 & $* * *$ & \multirow{2}{*}{ Adopted } \\
\hline $\begin{array}{c}\text { Job stress } \rightarrow \\
\text { Decline of personal sense } \\
\text { of accomplishment }\end{array}$ & .459 & .071 & .415 & 6.490 & $* * *$ & \\
\hline
\end{tabular}

As all the sub-hypotheses were adopted, the hypothesis that job stress would have a significant positive effect on job burnout was supported. 


\subsection{Control Role of Emotional Intelligence in the Effects of Job Stress on Job Burnout}

This study carried out a hierarchical regression analysis on the sub-hypotheses. It is about the control role of emotional intelligence on the causation between job stress and emotional exhaustion. To verify, this study performed a hierarchical regression analysis by inputting job stress, emotional intelligence, and interactions between job stress and emotional intelligence as independent variables and emotional exhaustion as a dependent variable. As shown in [Table 4], the regression models' conformity was significant, as the significant probabilities of Model 1, Model 2, and Model 3, in which job stress (an independent variable), emotional intelligence (control variable), and interaction were inputted, respectively, were $\mathrm{p}<.05$. As a result of verifying the significance of the explanation reliability and $\mathrm{R}^{2}$ change of the models, the models' explanation reliability $(\mathrm{p}<.05)$ and $\mathrm{R}^{2}$ change $(\mathrm{p}<.05)$ were statistically significant, and so the hypothesis was adopted.

[Table 4] Control Effect of Emotional Intelligence Affecting the Relationship between Job Stress and Emotional Exhaustion

\begin{tabular}{|c|c|c|c|c|c|c|}
\hline & \multicolumn{2}{|c|}{ Model 1} & \multicolumn{2}{|c|}{ Model 2} & \multicolumn{2}{|c|}{ Model 3} \\
\hline & $\beta$ & $t$ (sig.) & $\beta$ & $t$ (sig.) & $\beta$ & $t$ (sig.) \\
\hline (Constant) & - & $\begin{array}{c}-1.157 \\
(*)\end{array}$ & - & $\begin{array}{c}2.119 \\
(*)\end{array}$ & - & $\begin{array}{c}-.284 \\
(* * *)\end{array}$ \\
\hline Job stress & 0.725 & $\begin{array}{c}14.940 \\
(* * *)\end{array}$ & 0.730 & $\begin{array}{c}15.480 \\
(* * *)\end{array}$ & 1.014 & $\begin{array}{l}3.906 \\
(* * *)\end{array}$ \\
\hline Emotional intelligence & & & -0.170 & $\begin{array}{c}-3.906 \\
(* * *)\end{array}$ & 0.010 & $\begin{array}{c}0.057 \\
(*)\end{array}$ \\
\hline $\begin{array}{c}\text { Job stress* } \\
\text { Emotional intelligence }\end{array}$ & & & & & -0.344 & $\begin{array}{c}-1.112 \\
(*)\end{array}$ \\
\hline$R^{2}$ & & & & & & \\
\hline $\operatorname{adj} R^{2}$ & & & & & & \\
\hline$\Delta R^{2}$ & & & & $* *)$ & & \\
\hline
\end{tabular}

[Table 5] shows the controlling role of emotional intelligence working on the relationship between job stress and dehumanization. To verify this, a hierarchical analysis was carried out by inputting job stress, emotional intelligence, and interaction between job stress and emotional intelligence as 
independent variables and dehumanization as a dependent variable. According to the analytical result presented in [Table 5], as a result of checking the significance probabilities of Model 1, Model 2, and Model 3 in which job stress (independent variable), emotional intelligence (control variable), and interaction were inputted, respectively, all were $\mathrm{p}<.05$, and so the conformity of the regression models was effective. As a result of verifying the significance of the explanation reliability and $\mathrm{R}^{2}$ change, the explanation reliability $(\mathrm{p}<.05)$ and $\mathrm{R}^{2}$ change $(\mathrm{p}<.01)$ of the models were statistically significant. Therefore, the hypothesis was adopted.

[Table 5] Control Effect of Emotional Intelligence on the Relationship between Job Stress and Dehumanization

\begin{tabular}{|c|c|c|c|c|c|c|}
\hline & \multicolumn{2}{|c|}{ Model 1} & \multicolumn{2}{|c|}{ Model 2} & \multicolumn{2}{|c|}{ Model 3} \\
\hline & $\beta$ & $t$ (sig.) & $\beta$ & $t$ (sig.) & $\beta$ & $t$ (sig.) \\
\hline (Constant) & - & $\begin{array}{l}4.501 \\
(* * *)\end{array}$ & - & $\begin{array}{l}7.926 \\
(* * *)\end{array}$ & - & $\begin{array}{l}-.077 \\
(*)\end{array}$ \\
\hline Job stress & 0.409 & $\begin{array}{l}6.366 \\
(* * *)\end{array}$ & 0.421 & $\begin{array}{l}7.143 \\
(* * *)\end{array}$ & 1.326 & $\begin{array}{l}4.147 \\
(* * *)\end{array}$ \\
\hline Emotional intelligence & & & -0.367 & $\begin{array}{c}-6.231 \\
(* * *)\end{array}$ & 0.204 & $\begin{array}{c}0.985 \\
(*)\end{array}$ \\
\hline $\begin{array}{c}\text { Job stress* } \\
\text { Emotional intelligence }\end{array}$ & & & & & -1.099 & $\begin{array}{c}-2.877 \\
(* *)\end{array}$ \\
\hline$R^{2}$ & & & & & & \\
\hline $\operatorname{adj} R^{2}$ & & & & & & \\
\hline$\Delta R^{2}$ & & & 0.13 & $* *)$ & & \\
\hline
\end{tabular}

This table is about the controlling role of emotional intelligence on the causation between job stress and a decline in personal desire to accomplish. To verify this matter, a hierarchical regression analysis was carried out by inputting job stress, emotional intelligence, and interaction between job stress and emotional intelligence as independent variables and the decline of personal desire to accomplish as a dependent variable. 
According to the analytical result presented in [Table 6], as a result of checking the significance probabilities of Model 1, Model 2, and Model 3 in which job stress (independent variable), emotional intelligence (control variable), and interaction were inputted, respectively, all were $p<.05$, and so the conformity of the regression models was effective. As a result of verifying the significance of the explanation reliability and $\mathrm{R}^{2}$ change, the explanation reliability $(\mathrm{p}<.05)$ and $\mathrm{R}^{2}$ change $(\mathrm{p}<.01)$ of the models were statistically significant. Therefore, the hypothesis was adopted.

As all the sub-hypotheses were adopted, the hypothesis that emotional intelligence would play a controlling role in the effects of job stress on job burnout was supported.

[Table 6] Control Effect of Emotional Intelligence on the Relationship between Job Stress and the Decline of Personal Desire to Accomplish

\begin{tabular}{|c|c|c|c|c|c|c|}
\hline & \multicolumn{2}{|c|}{ Model 1} & \multicolumn{2}{|c|}{ Model 2} & \multicolumn{2}{|c|}{ Model 3} \\
\hline & $\beta$ & $t$ (sig.) & $\beta$ & $t$ (sig.) & $\beta$ & $t$ (sig.) \\
\hline (Constant) & - & $\begin{array}{l}4.014 \\
(* * *)\end{array}$ & - & $\begin{array}{l}9.564 \\
(* * *)\end{array}$ & - & $\begin{array}{c}-.738 \\
(*)\end{array}$ \\
\hline Job stress & 0.415 & $\begin{array}{l}6.490 \\
(* * *)\end{array}$ & 0.431 & $\begin{array}{l}7.816 \\
(* * *)\end{array}$ & 1.706 & $\begin{array}{l}5.861 \\
(* * *)\end{array}$ \\
\hline Emotional intelligence & & & -0.466 & $\begin{array}{l}-8.445 \\
(* * *)\end{array}$ & 0.339 & $\begin{array}{l}1.802 \\
(*)\end{array}$ \\
\hline $\begin{array}{c}\text { Job stress* } \\
\text { Emotional intelligence }\end{array}$ & & & & & -1.548 & $\begin{array}{l}4.454 \\
(* * *)\end{array}$ \\
\hline$R^{2}$ & & & & & & \\
\hline $\operatorname{adj} R^{2}$ & & & & & & \\
\hline$\Delta R^{2}$ & & & 0.2 & $* *)$ & & $(* * *)$ \\
\hline
\end{tabular}

\section{Conclusion and Implications}

This study aimed to: provide the implications on the relationship between personal relations and human service workers' job stress, emotional intelligence, and job burnout at social and policy levels; form a bond of sympathy; providing detailed job guidelines for human service workers in the social welfare field, putting importance on emotional management and high-quality service and creating 
learning data; and offer guidelines for the efficient operations of the long-term home care institutions, as well as the self-development and quality of life improvement of nursing care workers, which are the core human resources of the long-term care insurance system. First, nursing care workers' job stress was verified to affect job burnout, and relations with senior workers, outsized roles, and rewards were the factors raising job burnout among the nursing care workers. They were confirmed to affect emotional exhaustion significantly. Emotional exhaustion includes one's own emotion, interest, and belief. The most important factor causing job burnout to a person is emotional exhaustion, and it can be a cause of dehumanization and a decline in a personal sense of accomplishment[8]. As a result of the study, emotional exhaustion should be thoroughly and effectively managed. Job environment improvement is judged to be necessary through job training on organizational management for facility heads and managers and by benchmarking via a visit to excellent institutions. The government and the institutions need to reconsider whether adequate occupational and economic rewards are offered to nursing care workers. If the job stress and job burnout of nursing care workers providing human service can be eased through manager training on management of workers and the improvement of nursing care workers, the service quality for senior citizens will improve as much as the nursing care workers' satisfaction. The institutions' competitiveness enhancement that was left to facility heads and service sector satisfaction would be revealed through private facilities' expansion.

Second, emotional intelligence was analyzed to play a controlling role in the effects of nursing care workers' job stress on job burnout. Emotional intelligence in the relationship between nursing care workers' job stress and job burnout showed control effects on the three sub-factors of job burnout, namely emotional exhaustion, dehumanization, and a decline in personal desire to accomplish. Through this, it is understood that emotional intelligence is essential in easing job burnout caused by nursing care workers' job stress. The government should use the long-term care insurance system's result, and a systematized emotional capability development system should be developed and implemented. Based on these factors, nursing homes should carry out emotional intelligence training for nursing care workers to actively cope with job stress.

\section{References}

[1] K. H. Han, The Moderating Effects of Negative Affectivity on the Relationships Between the Job Characteristics and Burnout Outcomes, Korea Journal of Business Administration, (2007), Vol.20, No.3, pp.1475-1498, UCI : G704000789.2007.20.3.010

[2] Y. S. Yoon, Burnout Among Care Helpers In-Home Service Centers: Focusing on the Impact of Job Stress, Calling, and Supervision, Department of Social Welfare Graduate School of Social Welfare, Myongji University, Master's thesis, (2019)

[3] J. E. Jung, The Effects of Emotional Leadership Upon Self-Efficacy and Organizational Performance: Focusing on Moderating Effects of Emotional Intelligence, Department of Hotel Management Graduate School, Kyonggi University, Doctor dissertation, (2015)

[4] K. J. Yoon, M. N. Ha, J. Y. Kim, S. Y. Lee, H. J. Im, A. S. Shin, S. S. Hwang, J. S. Kim, D. H. Kang, S. H. Cho, The Effects of Job Stress on the Autonomic Nerve Activity of Workers in Manufacturing Industry, Annals of Occupational and Environmental Medicine, (2002), Vol.14, No.3, pp.280-287, UCI : G704-000627.2002.14.3.005

[5] J. M. Ivancevich, M. T. Matteson, C. Preston, Occupational Stress, Type A Behavior, and Physical Well Being, Academy of Management Journal, (1982), Vol.25, No.2, pp.373-391.

[6] S. K. An, A Study on the Relationship Between Professional Identity and in- Service Training and Burn-out: Focused on Social Workers in Community Welfare Center in Seoul, Dongguk University, Master's thesis, (2000)

[7] C. S. Wong, K. S. Law, The Effects of Leader and Follower Emotional Intelligence on Performance and Attitude: An 
Effects of the Job Stress of Nursing Care Workers at Nursing Homes on Burnout

- Focusing on the Control Effects of Emotional Intelligence -

Exploratory Study, The Leadership Quarterly, (2002), Vol.13, No.3, pp.243-274, https://doi.org/10.1016/S10489843(02)00099-1

[8] J. Y. Hong, The Influence of Emotional Labor and Job Burnout of the Long-term Care Workers on The Turnover Intention, Daegu Haany University, Doctor dissertation, (2014) 